\title{
Experimental investigation and Computational fluid dynamics analysis of heat pipe with fin at condenser
}

\author{
G T Sawant ${ }^{*}$ and D S Patil \\ †Department of Mechanical Engineering, Savitribai Phule Pune University, G H Raisoni college of engineering and Mgnt, Wagholi, Pune, India
}

Accepted 15 June 2016, Available online 20 June 2016, Special Issue-5 (June 2016)

\begin{abstract}
In this experimental study of heat transfer present the Investigation of thermal performance of heat pipe with fins attached at the condenser section. The material and working fluid used for heat pipe are of different kind. Heat pipes are constructed and the experiments are conducted to determine the surface temperature at steady and transient conditions, heat transfer rate, heat transfer coefficient for different boundary conditions at different input power in the evaporator section and cooling the condenser section by air. The experimental results show that the rate of heat transfer increases in the heat pipe after addition of fins in the condenser section. For Horizontal position acetone as working fluid is preferred due to its thermal efficiency increases with increasing power input. Copper is used as container material at low power input but if power input is more than 42 watt Stainless steel is preferred due to high thermal efficiency.
\end{abstract}

Keywords: Heat pipe, Heat transfer coefficient, sonic limit, entrainment limit, capillary force, thermal resistance.

\section{Introduction}

The heat pipe is a vapor and liquid phase change device of very high thermal conductance that transfers heat from a heat source (hot reservoir) to a heat sink (cold reservoir) using capillary forces generated by wick material and the working fluid. It is similar to the thermosyphon in few respects. It combines the principles of both thermal conductivity and phase transition to efficiently manage the transfer of heat between two interfaces. It is referred as superconductor of heat due to their fast heat transfer capability with low heat loss. Heat pipe consists of the evaporators section, adiabatic section, and condenser section. There are three regions separated as vapor region, wick region and the wall region. The working fluid is assumed to be liquid phase in the wick region and vapor phase in the vapor region. Thermal input at the evaporator region vaporizes the working fluid and this vapor travels to the condenser section through the vapor region. At the condenser region, the vapor of the working fluid condenses by rejecting the latent heat. The condensate returns to the evaporator by means of capillary action in the wick.

When the condenser surface should be exposed with circulating water with high convective heat transfer coefficient value or higher heat transfer area is required with addition of fins in the condenser section then heat pipe works effectively (Velraj Ramalingam,

*Corresponding author: G T Sawant
2011).The amount of liquid filled in the heat pipe is affecting the performance parameters of heat pipe. Therefore, the optimum liquid fill ratio is identified in terms of lower temperature difference and thermal resistance and higher heat transfer coefficient. The fill ratios of working fluid greater than $85 \%$ of volume of evaporator increases the heat transfer coefficient, decrease thermal resistance and also there is reduction in temperature difference across the evaporator and condenser (K. Mozumder, 2010).The orientation of the heat pipe is important for the practical applications: favorable tilt and adverse tilt. It is preferable to operate heat pipe in a favorable tilt Position so that heat transfer capacity can be increased (R.Manimaran, 2012).

From the previous literature on heat pipe, it has already known that the performance of heat pipe is depends on the various parameters such as the fluid fill ratio, container material, orientation of heat pipe etc. Most of this work is done by using water jacket at the condenser section or directly exposing same to the atmosphere. It seems that there is less work is done on the study of performance of heat pipe with fins at condenser section experimentally and the validation of results. Also the work is not found on the combination of the copper as container material, the acetone as working fluid and the phosphorous bronze as a wick material. The objective of this work is to investigate the performance of heat pipe with fin at condenser theoretically and experimentally. Also the validation of the results is done using software. 


\section{Heat pipe-Fundamentals}

The three basic components of heat pipe are the working fluid, wick structure and the container. These components determine the operational characteristics of heat pipe.
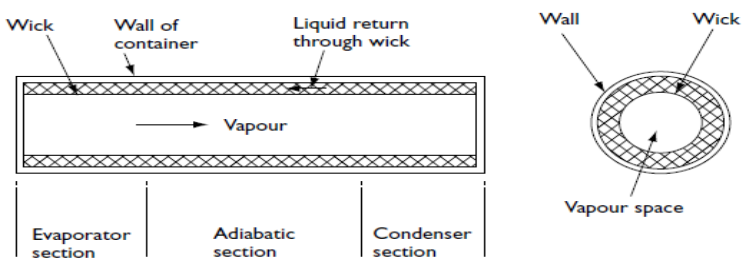

Fig.2.1The main regions of the heat pipe

One of the most important considerations to choose the material for the heat pipe container and the wick is its compatibility with the working fluid. The working fluid requires good thermal stability properties at the specified operational temperature and pressure. The operational temperature range for the working fluid lies between its triple point and its critical point for liquid to exist in the wicking material. The wick structure and working fluid generate the capillary forces required to 1. Pump liquid from the condenser to evaporator and 2. Keep liquid evenly distributed in the wicking material. The materials of components selected for this study are given below as:-

Table 2.1Heat pipe components material

\begin{tabular}{|c|c|c|c|c|}
\hline Pipe No. & $\begin{array}{c}\text { Working } \\
\text { Fluid }\end{array}$ & $\begin{array}{c}\text { Container } \\
\text { Material }\end{array}$ & $\begin{array}{c}\text { Wick } \\
\text { Structure }\end{array}$ & $\begin{array}{c}\text { Wick } \\
\text { Material }\end{array}$ \\
\hline Pipe 1. & Water & Copper & Screen Mesh & Phosphorus \\
\hline Pipe 2. & Acetone & Copper & Screen Mesh & Phosphorus \\
\hline Pipe 3. & Water & $\begin{array}{c}\text { Stainless } \\
\text { steel }\end{array}$ & Screen Mesh & Phosphorus \\
\hline
\end{tabular}

\section{Heat transfer and fluid flow theory}

The overall temperature difference between the heat sink and the heat source is an important characteristic while utilizing heat pipe in thermal control systems .As the heat transfer occurs from the heat source to the heat sink, each part of the heat pipe have an individual thermal resistance. The combined resistances provide a mechanism to model the overall thermal resistance. The overall thermal resistance of a heat pipe should be low for proper working of heat pipe.

$$
R=\frac{T_{e}-T_{c}}{Q}
$$

There are various heat transfer limitations occurs during the working of heat pipe depending on the working fluid, the wick structure, the container, the dimensions of the heat pipe and the heat pipe operational temperature. Limitations can be divided into two primary categories: limits that result in heat pipe failure (Failure limit) and limit that do not fail the heat pipe operation (Non failure limit). All failure limitations are characterized by insufficient liquid flow to the evaporator for a given heat input due to which the evaporator wick structure gets dry out. The limitations divided as: - Failure limits: Capillary limit, Boiling limit and Entrainment limit. Non failure limit: Viscous limit, sonic limit, Condenser limit. The composite curve enclosing the region in Figure 3.1 shows the limitations of heat pipe.

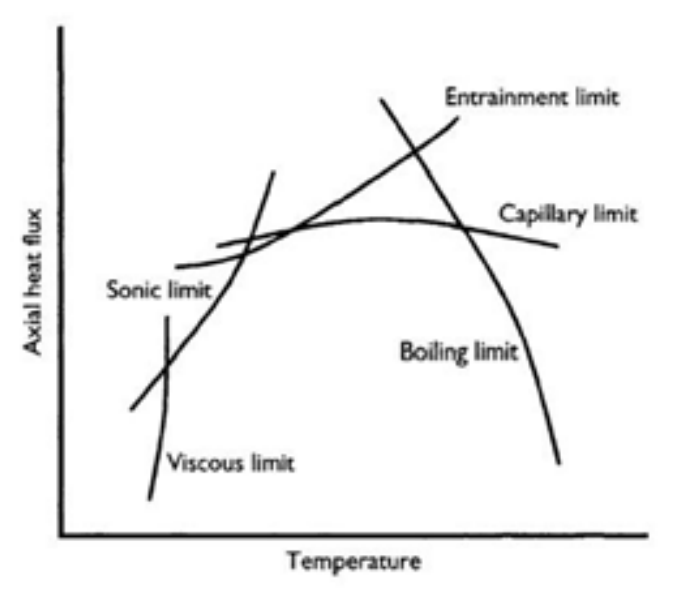

Fig.3.1 Limitations in the heat pipe

Capillary Limit: When the frictional pressure losses are not overcome by the net capillary forces generated by the vapor-liquid interfaces in the evaporator and condenser then capillary limitations occurs.

$$
\begin{gathered}
\Delta \mathrm{P}_{\mathrm{c}}=\Delta P_{l}+\Delta P_{g}+\Delta P_{v} \\
r_{c}=\frac{w+d_{w}}{2} \\
\Delta \mathrm{P}_{\mathrm{c}}=\frac{2 \sigma \cos \theta}{\mathrm{r}_{\mathrm{c}}} \\
\varepsilon=1-\frac{1.05 \times \pi \times N \times D}{4} \\
K=\frac{d_{w}^{2} \times(1-\varepsilon)^{3}}{66.6 \times \varepsilon^{2}} \\
\Delta P_{l}=\frac{\mu_{l} \times Q_{c} \times L_{e f f}}{\rho_{l} \times L \times A_{w} \times K} \\
\Delta P_{g}=\rho_{l} \times g \times l_{e f f} \times \operatorname{SIN\emptyset } \\
\Delta P_{v}=0.9^{12} \times k_{v} \times Q
\end{gathered}
$$

Boiling Limit: The boiling limitation in the heat pipe occurs when the degree of superheat (liquid) in the evaporator is required large to cause the nucleation of vapor bubbles on the surface of wick or the container.

$$
l_{\text {eff }}=L_{a}+\frac{L_{e}+L_{c}}{2}
$$




$$
\begin{gathered}
k_{e f f}=\frac{k_{l}\left[\left(k_{A}+k_{w}\right)-(1-\varepsilon)\left(k_{l}-k_{w}\right)\right]}{\left(k_{A}+k_{w}\right)+(1-\varepsilon)\left(k_{l}-k_{w}\right)} \\
Q_{b}=\frac{2 \pi l_{e f f} \times k_{e f f} \times T_{v}}{A_{v} \times h_{f g} \times \rho_{v} \times \ln \left(\frac{r_{i}}{r_{v}}\right)}\left[\frac{2 \sigma}{r_{n}}-\left(\Delta \mathrm{P}_{\mathrm{c}}\right)_{\max }\right]
\end{gathered}
$$

Entrainment Limit: The entrainment limitation in the heat pipes develops when the vapor mass flow rate is large enough to shear droplets of liquid of the wick surface causing dry out in the evaporator.

$$
Q_{e}=\pi r_{v}{ }^{2} L \sqrt{\frac{2 \pi \rho_{v} \sigma_{l}}{z}}
$$

Sonic limit: The sonic limitation can occur in the heat pipe during start up at low temperature.

$$
Q_{s}=\rho_{v} L \sqrt{\frac{r R T_{v}}{2(r-1)}}
$$

The Merit number: It will be given, with reference to the capillary limit, that if vapor pressure loss and gravitational head can be neglected then the properties of the working fluid which determine the maximum heat transport can be combined to form a figure of merit, $\mathrm{M}$.

$$
M=\frac{\rho_{l} \times \sigma \times L}{\mu_{l}}
$$

For the presented work the values of limitations of heat pipe calculated are:

Table 3.1Limitations of the Heat pipe

\begin{tabular}{|c|c|c|}
\hline Sr.No. & Limitations & Values (watt) \\
\hline 1 & Capillary limit & 565 \\
\hline 2 & Boiling limit & 3115.16 \\
\hline 3 & Entrainment limit & 92000 \\
\hline 4 & Sonic limit & 200000 \\
\hline
\end{tabular}

\section{Experimental set up}

The experimental set-up used in this investigation is shown in fig 4.1 .

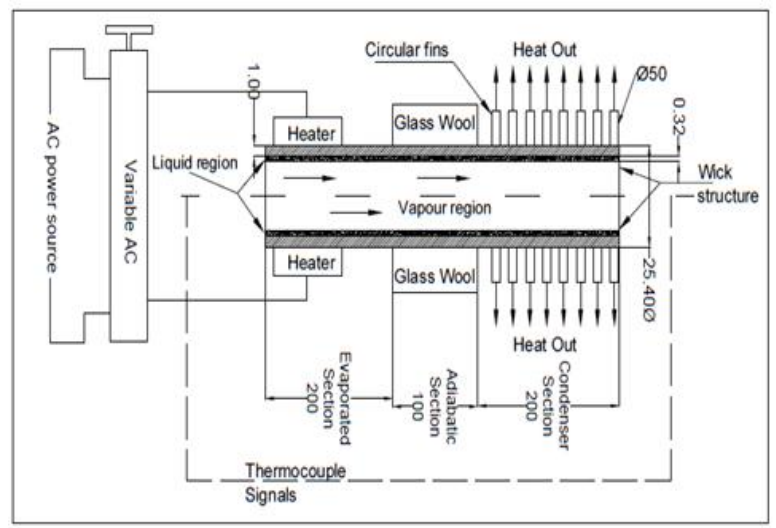

Fig.4.1Experimental set up
The specifications of the heat pipe are given in table 4.1.The maximum heat transport capability of heat pipe is determined from their limitations and these are find out using data given in table 4.1.

Table 4.1Specifications of the Heat pipe

\begin{tabular}{|c|c|c|}
\hline Sr. No. & Description & Dimension \\
\hline 1 & Heat pipe total length (mm) & 500 \\
\hline 2 & Evaporator section length (mm) & 200 \\
\hline 3 & Adiabatic section length $(\mathrm{mm})$ & 100 \\
\hline 4 & Condenser section length $(\mathrm{mm})$ & 200 \\
\hline 5 & Heat pipe inner diameter $(\mathrm{mm})$ & 23.4 \\
\hline 6 & Heat pipe outer diameter $(\mathrm{mm})$ & 25.4 \\
\hline 7 & Heat pipe wall thickness $(\mathrm{mm})$ & 1 \\
\hline 8 & Vapor core diameter $(\mathrm{mm})$ & 22.76 \\
\hline 9 & Wick area (m $\left.{ }^{2}\right)$ & $2.3202 \mathrm{e}-5$ \\
\hline 10 & Type of fin & Annular Fin \\
\hline 11 & Number of fin & 41 \\
\hline 12 & Fin outer diameter (mm) & 50 \\
\hline
\end{tabular}

Table 4.2 gives the geometric properties of the wire mesh wick.

Table 4.2 Specification of wick

\begin{tabular}{|c|c|c|}
\hline Sr. No. & Description & Dimension \\
\hline 1 & Screen Mesh Number & 180 \\
\hline 2 & Wire Diameter (mm) & 0.04 \\
\hline 3 & Wire spacing (mm) & 0.0989 \\
\hline 4 & Wick Porosity & 0.7625 \\
\hline 5 & Number of layer & 4 \\
\hline
\end{tabular}

Table 4.3Specification of setup components

\begin{tabular}{|c|c|c|}
\hline Sr. No. & Description & Specifications \\
\hline 1 & Insulating material & Glass Wool \\
\hline 2 & Type of thermocouple & K-Type \\
\hline 3 & Number of thermocouple & 11 \\
\hline 4 & Type of heater & Band Heater \\
\hline 5 & Number of heater & 3 \\
\hline
\end{tabular}

The locations of thermocouples and heat pipe under study with control panel are shown in the following fig.4.2.and fig.4.3 respectively. 


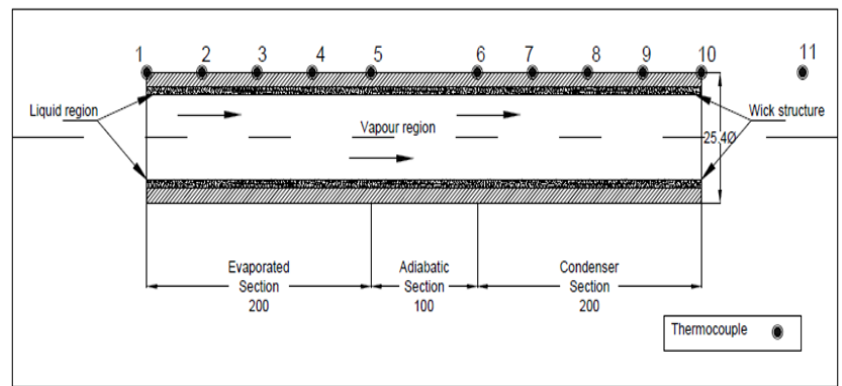

Fig.4.2 Locations of thermocouple

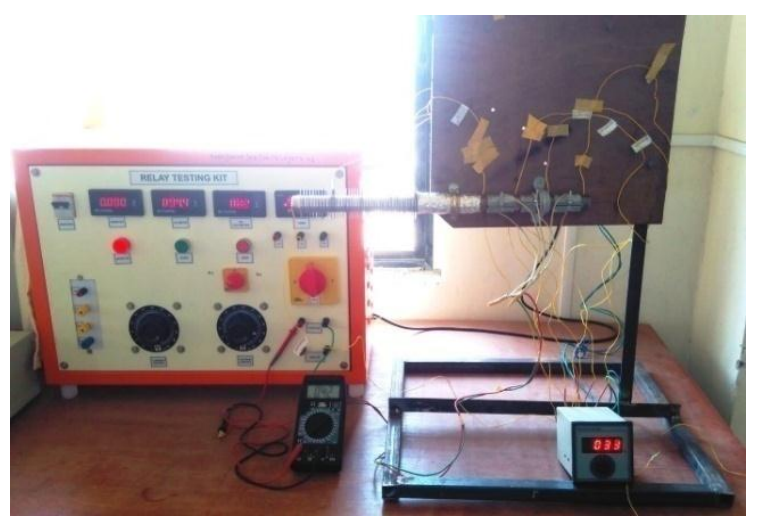

Fig.4.3 Heat pipe under study with control panel

\section{Results and Discussion}

The experiment is performed on three different sets of heat pipe with different position and heat input.

Pipe No 1:

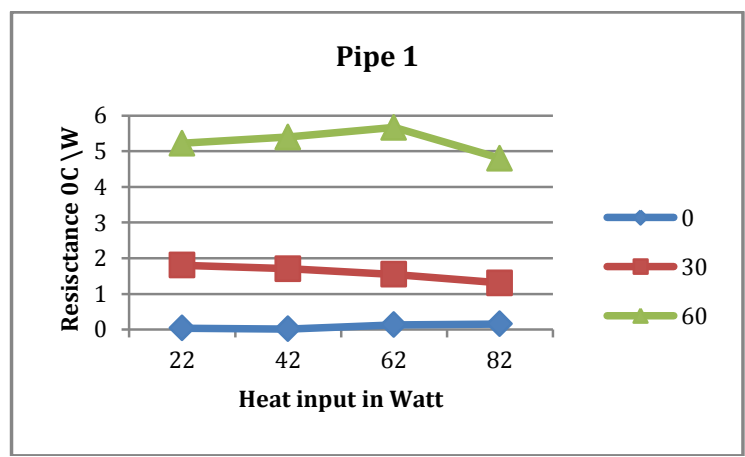

Fig.5.1 Thermal Resistance vs power

From the fig. 5.1, it is clear that the Thermal resistance of heat pipe is decreases with the increase in heat load. At the low heat input, the thermal resistance at all three inclination angles are high because of the relatively solid liquid film in the evaporator section. When the angle of inclination increases then the thermal resistance increases as the fluid flow has to work against the gravitational force. The thermal resistance is less at horizontal position (lies between 0.03 to $\left.0.2{ }^{\circ} \mathrm{C} / \mathrm{W}\right)$. At $30^{0}$ inclinations resistance is decrease with increasing power input (lies between
1.30 to $1.80{ }^{\circ} \mathrm{C} / \mathrm{W}$ ). At $60^{\circ}$ inclination resistances are higher and increase with power input (lies between 4 to $5^{\circ} \mathrm{C} / \mathrm{W}$ ).

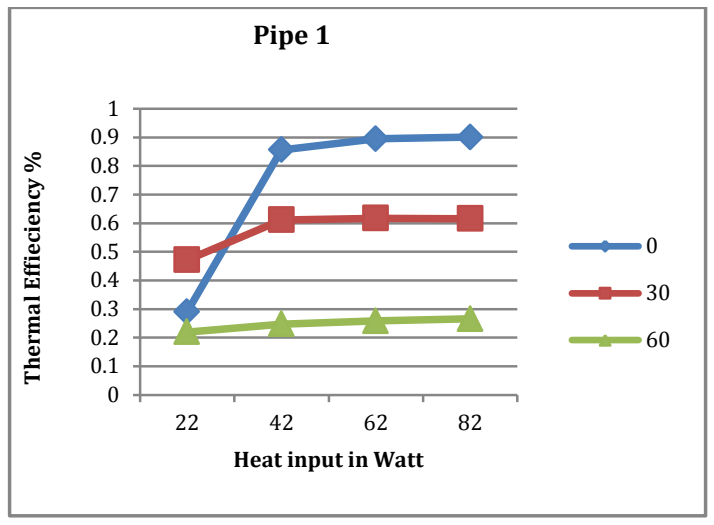

Fig 5.2 Thermal Efficiency vs power

Fig.5.2 shows that the thermal efficiency of heat pipe increases with the increase in heat inputs at evaporator section and decreases with angle of inclination. It is due to that at higher heat input, the values of thermal resistance are low. For Horizontal position Efficiency is higher lies between 30\% to $90 \%$ because merit number is increase with increasing temperature.

Pipe No 2:

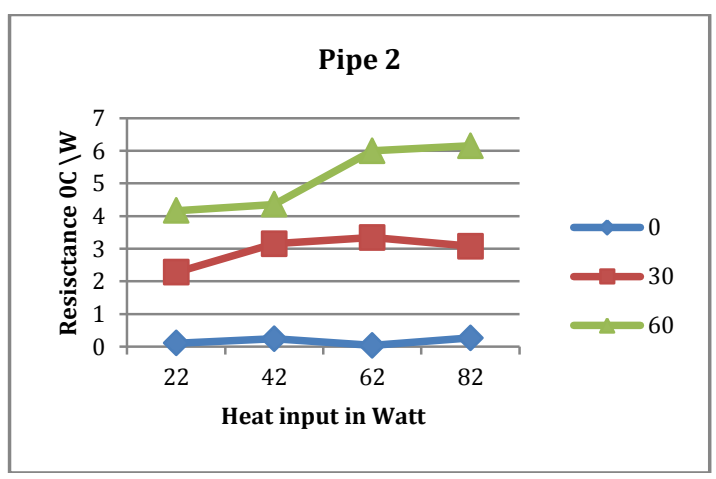

Fig.5.3 Thermal Resistance vs power

Fig. 5.3 shows Thermal resistances is increase with increasing inclination and also increasing input power.

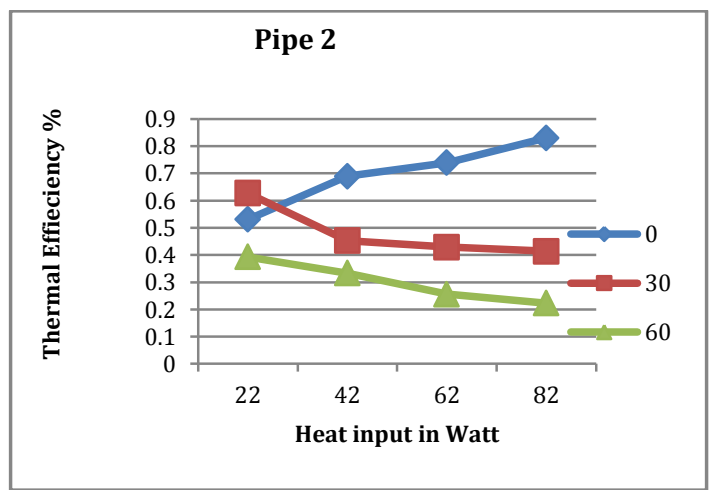

Fig 5.4 Thermal Efficiency vs power 
Fig 5.4 Shows, Thermal efficiency is in increase with increasing power ate horizontal position efficiency decrease with inclination.

Pipe No 3:

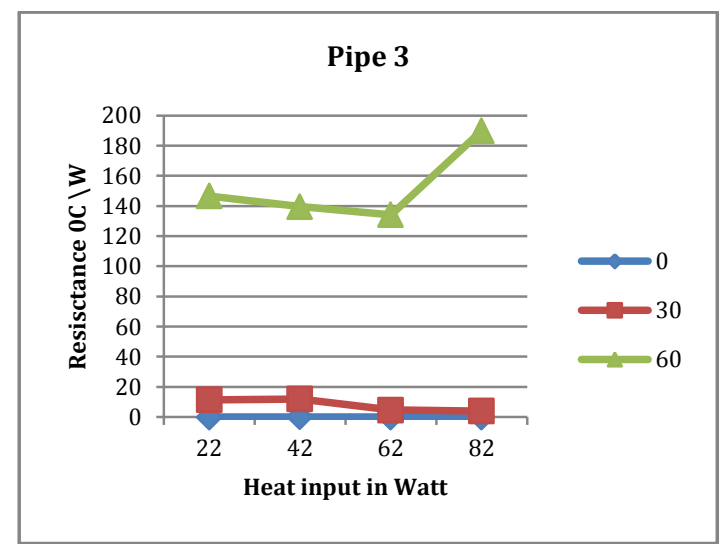

Fig.5.5Thermal Resistance vs power

Fig. 5.5 shows the graph of thermal resistance vs heat input of stainless steel heat pipe with working fluid as water. From fig. 5.1 and fig. 5.5, it is clear that the thermal resistance of copper heat pipe is always less than the stainless steel heat pipe. So generally the copper is preferred as the heat pipe container material. During performing experiment, it is observed that the heat pipe not work at $60^{\circ}$ because the thermal resistance is higher (Lies between 130 to $190{ }^{\circ} \mathrm{C} / \mathrm{W}$ ).

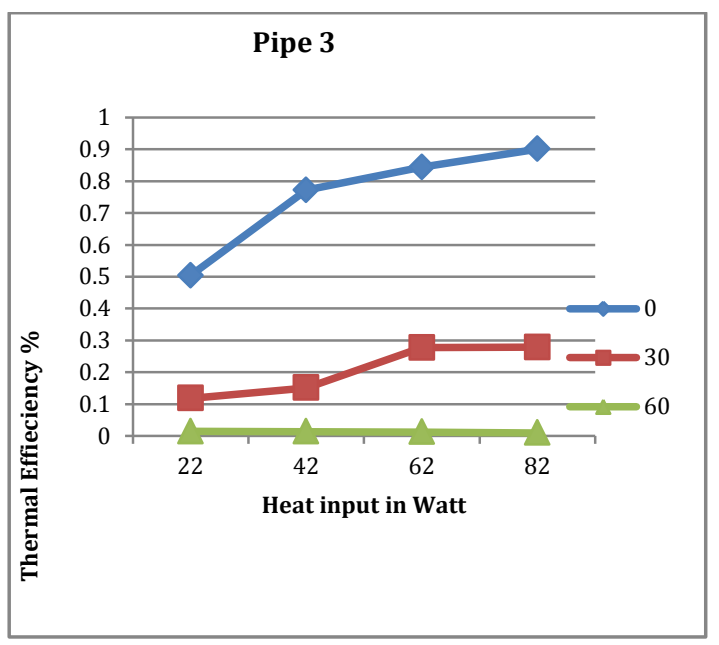

Fig 5.6 Thermal Efficiency vs power

Fig. 5.6 shows that the Thermal efficiency is increase with increasing power input but this type of pipe is not suitable for inclination due to low thermal efficiency.

From the analysis, it is found that the heat transfer rate at the condenser section is increases due to fin attached at that section. The copper heat pipe is more effective than the stainless steel heat pipe with same working fluid.

The CFD analysis is performed for the configuration used in similar to the experimental investigation, adding the fin in the condenser section. The results obtained from the CFD analysis for the heat pipe with surface heat flux in the evaporator sides are presented in Figures given below.
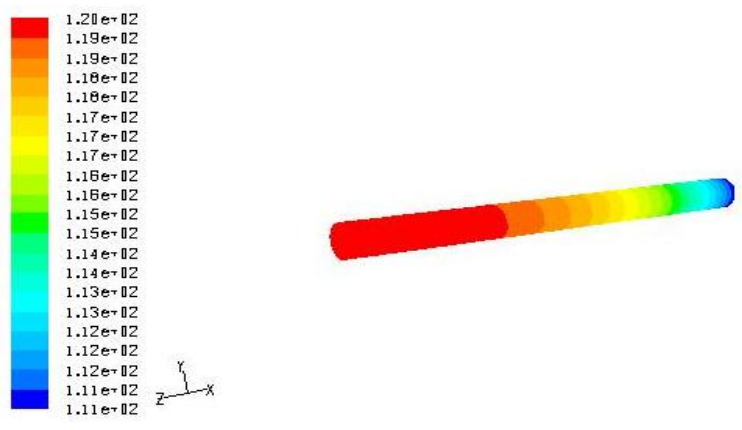

Fig.5.7 Evaporator surface temperature $\left({ }^{\circ} \mathrm{C}\right) 60 \mathrm{~W}$
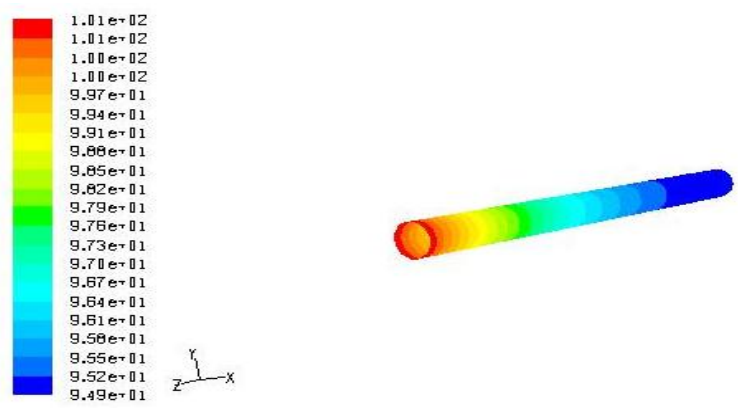

Fig.5.8 Evaporator surface temperature $\left({ }^{\circ} \mathrm{C}\right)$ at $60 \mathrm{~W}$

Figure 5.7 shows the CFD result of the steady state surface temperature distribution within the evaporator section of the heat pipe where temperature is getting reduced along the surfaces of the heat pipe. As length increases the process of evaporation process are clearly visible by the uniform surface temperature in the respective zone. The constant temperature of the surface in the evaporator zone is continued along its length up to adiabatic zone as there is no heat loss in this zone. As surface heat flux in the evaporator increases the operating temperature of the heat also increases, when the heat pipe attained steady-state the evaporator surface reaches an average temperature of $120^{\circ} \mathrm{C}$

Figure 5.8 shows the CFD result of the steady state surface temperature distribution within the condenser section of the heat pipe, The temperature difference is very minimal or nearing zero at three locations i.e. evaporator zone with highest heating intensity, end of the adiabatic zone and at the end of condenser zone. In an ideal heat pipe for the entire zone the temperature difference between the vapor and the surface should approach zero since evaporation and condensation are the processes with high heat transfer coefficient. As the temperature reduces in the condenser region due to involvement of fins, the condenser surface reaches an average temperature of $94.9^{\circ} \mathrm{C}$ at the end of condenser section. 


\section{Conclusions}

The present work is focused on Heat pipe with fin at condenser section having different working fluid as well as different container material. During the course of dissertation, an attempt is made for experimental study of heat pipe with different power input and inclination of pipe without use of gravity. The temperature variation through the length of heat pipe is obtained by set of thermocouple. The silent features of the present work may be summarized as follows.

For Different working fluid

1) For Horizontal position acetone as working fluid is preferred due to its thermal efficiency is increase with increasing power input.

2) For inclination $\left(30^{\circ}\right)$ Water as working fluid is preferred its thermal efficiency are increase with increasing power input.

3) For inclination $\left(60^{\circ}\right)$ Acetone as working fluid is used but prefer for low input at high input the thermal efficiency also decrease.

\section{For Different Container material}

1) For Horizontal position copper is used as container material at low power input but power input is more than 42 watt stainless steel is preferred due to high thermal efficiency.

2) For inclination $\left(30^{\circ}\right)$ copper is used as container material as compare to stainless steel.

3) For inclination $\left(60^{\circ}\right)$ copper is used as container material as compare to stainless steel. At this condition stainless steel heat pipe are fail and not working for long time.

\section{For Different Inclination}

1) For Horizontal position all pipe are suitable in which acetone is preferred for low input power, copper and stainless steel pipe is preferred as high input power condition.

2) For inclination $\left(30^{\circ}\right)$ water is used as a working fluid to get higher thermal efficiency for above 42 watt and below 42 watt Acetone is preferred as a working fluid.
3) For inclination $\left(60^{\circ}\right)$ Acetone is used as a working fluid to get higher thermal efficiency.

\section{References}

Arul Selvan Annamalai and Velraj Ramalingam (2011), Experimental investigation and computational fluid dynamics analysis of an air cooled condenser heat pipe, Thermal Science, Vol. 15, pp. 759-772.

A. K. Mozumder (2010), Performance of heat pipe for different working fluids and fill ratios, Journal of Mechanical Engineering, Vol. ME 41, pp.-96-102.

Rathinasamy Senthilkumar (2011), Thermal analysis of heat pipe using self-rewetting fluids, Thermal Science, Vol. 15, pp.-879-888.

R.Manimaran (2012), Factors affecting the thermal performance of heat pipe -a review, Journal of Engineering Research and Studies, Vol. III, pp-.20-24.

K.V.Paiva, M.B.H. Mantelli (2015), Wire plate and sintered hybrid heat pipe, International journal of thermal science, Vol.95, pp.-36-51.

A. Victor Richardson (2015), Heat transfer enhancement of heat pipe using $\mathrm{tiO}_{2}$ Nanofluid, International journal of engineering research, Vol.3. pp.-294-303.

A. H. Howard, G. P. Peterson (1995), Investigation of a Heat Pipe Array for Convective Cooling, Journal of Electronic Packing, Vol. 117, pp.-208-214.

X. Yang, Y.Y.Yan, D. Mullen (2012), Recent developments of light weight, high performance heat pipes, Applied thermal engineering, Vol. 33-34, pp.-1-14.

Peter Meisel, Matthias (2015), Design and manufacturing of ceramic heat pipes for high temperature applications, Applied thermal engineering, Vol. 75, pp-692-699.

Zirong Lin, Shuangfeng (2011), Experimental study on effective range of miniature oscillating heat pipes, Applied thermal engineering, Vol-31, pp-880-886.

Leonard L. Vasilliev (2005), Heat pipes in modern heat exchangers, Applied thermal engineering, Vol-25, pp-1-19.

R. Manimaran, K. Palaniradja, N. Alagumurthi, J. Hussain (2012), Factors affecting the thermal performance of heat pipe-A review, Journal of Engineering Research and Studies, Vol. III, 20-24

Jie Yi (2003), Heat transfer characteristics of the evaporator section using small helical coiled pipes in a looped heat pipe, Applied thermal engineering, Vol.-23, pp-89-99. 